\title{
Interactions between volatiles and char during pyrolysis of biomass: Reactive species determining and reaction over functionalized carbon nanotubes
}

\author{
Yong Huang, ${ }^{l}$ Yalun Hu, ${ }^{1}$ Jun-ichiro Hayashi, ${ }^{2,3,4,}$ and Yunming Fang ${ }^{1, *}$ \\ ${ }^{1}$ Department of Chemical Engineering, Beijing University of Chemical Technology, \\ 100029, Beijing, China \\ ${ }^{2}$ Institute for Materials Chemistry and Engineering, Kyushu University, 6-10, Kasuga \\ Koen, Kasuga 816-8580, Japan \\ ${ }^{3}$ Interdisciplinary Graduate School of Engineering Sciences, Kyushu University, 6-10, \\ Kasuga Koen, Kasuga 816-8580, Japan \\ ${ }^{4}$ Research and Education Center of Carbon Resources, Kyushu University, 6-10, Kasuga
} Koen, Kasuga 816-8580, Japan

*E-mail: junichiro_hayashi@cm.kyushu-u.ac.jp; E-mail: fangym@mail.buct.edu.cn 


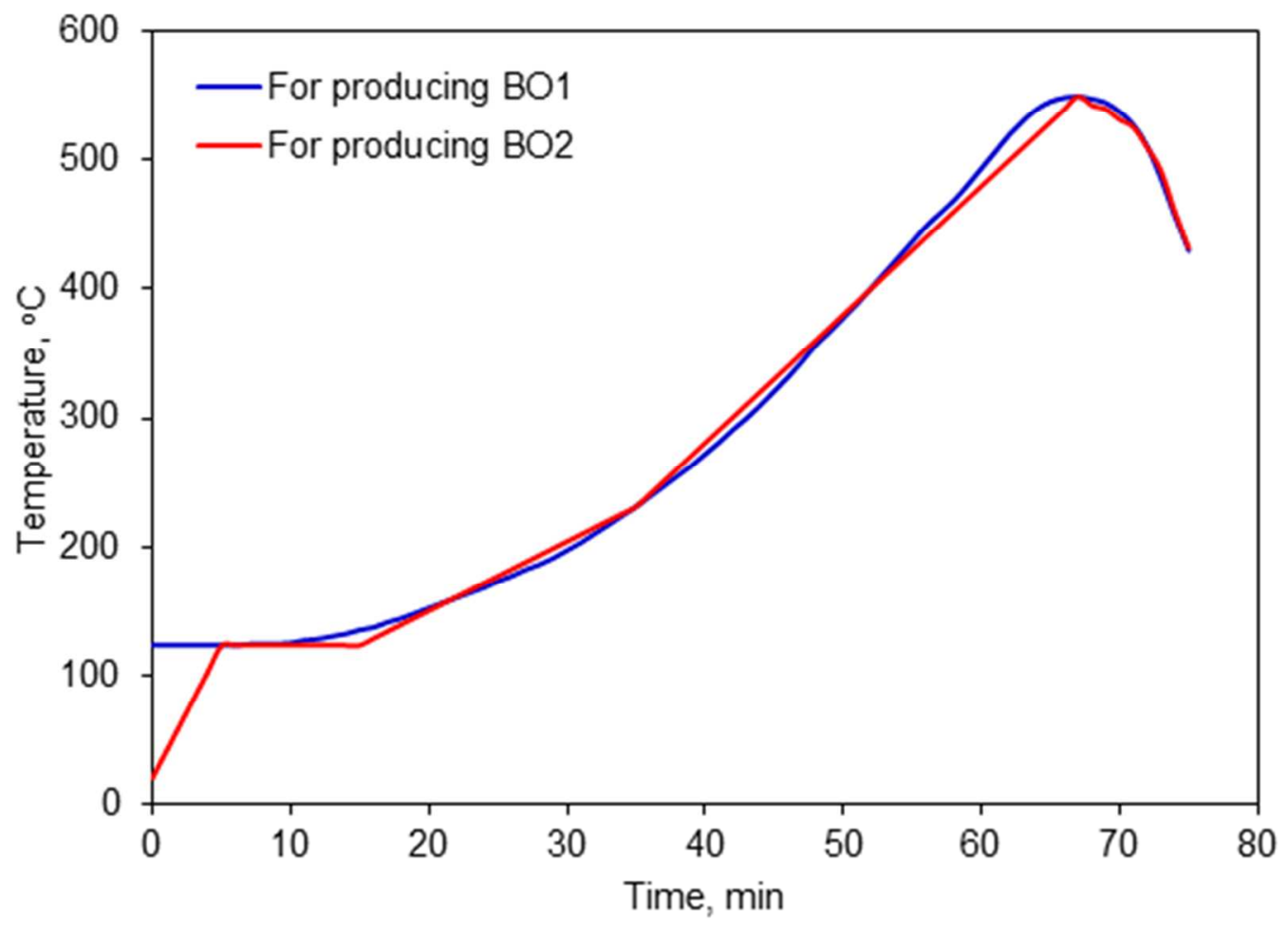

Figure S1. Temperature history of samples for producing BO1 and BO2. 


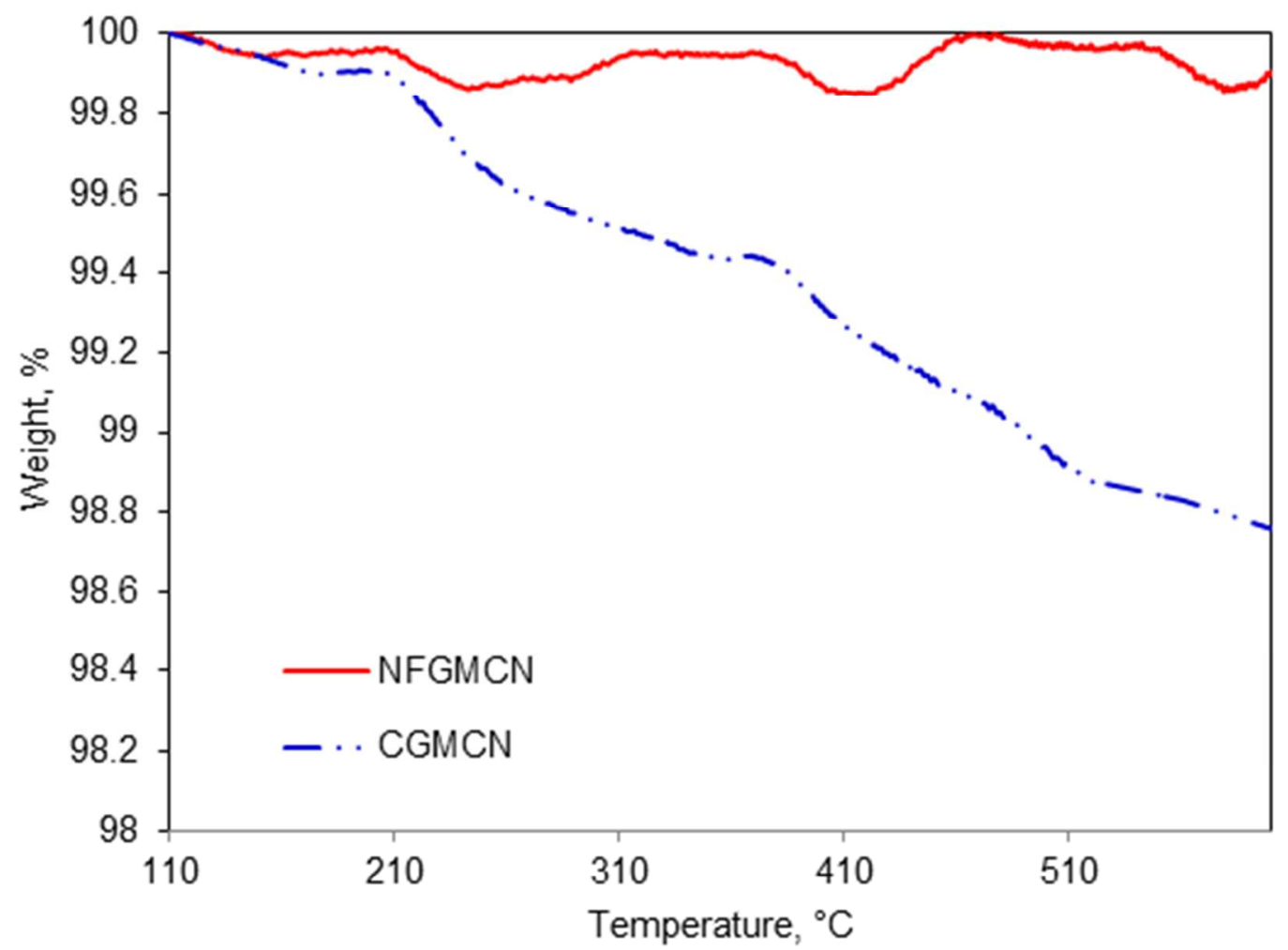

Figure S2. TGA curves of NFGMCN and CGMCN under $\mathrm{N}_{2}$ flow. The temperature profile was as follows: temperature holding at $110{ }^{\circ} \mathrm{C}$ for $10 \mathrm{~min}$, heating to $600{ }^{\circ} \mathrm{C}$ at a rate of $10^{\circ} \mathrm{C} / \mathrm{min}$. The data obtained after $10 \mathrm{~min}$ was employed to plot the figure. 